\title{
EL DESPOBLADO DE LAGUNAS (ZARAGOZA) EN LA BAJA EDAD MEDIA. NUEVAS APORTACIONES
}

\author{
THE DESERTED VILLAGE OF LAGUNAS (ZARAGOZA) \\ IN THE LATE MIDDLE AGES: \\ NEW CONTRIBUTIONS
}

María Teresa IRANZO MuÑío

Archivo Histórico Provincial de Zaragoza miranzom@aragon.es

Resumen: El hallazgo casual de un documento en pergamino con la carta de población otorgada a Lagunas en 1316 por la Comunidad de aldeas de Daroca permite puntualizar algunos aspectos tratados en un artículo anterior y extender el foco de atención hacia la dinámica de las rentas eclesiásticas en la baja Edad Media aragonesa.

Palabras clave: siglo XIV, carta de población, rentas eclesiásticas, Lagunas, Comunidad de aldeas de Daroca, Aragón.

\begin{abstract}
The casual discovery of a parchment document with the population charter granted to Lagunas in 1316 by the Comunidad de Aldeas de Daroca, allows us to point out some aspects dealt with in a previous article and to extend the focus of attention to the dynamics of ecclesiastical incomes in the Late Aragonese Middle Ages.

Keywords: $14^{\text {th }}$ Century, population charter, ecclesiastical incomes, Lagunas, Comunidad de aldeas de Daroca, Aragon.
\end{abstract}




\section{Justificación ${ }^{1}$}

En el curso de una revisión de la extensa serie de Pleitos Civiles de la Real Audiencia de Aragón, se localizaron descontextualizados dos documentos que vienen a arrojar nueva luz sobre un asunto que tratamos en coautoría con el arqueólogo Julián Ortega en esta misma revista, Aragón en la Edad Media, bajo el título «Disciplina agraria y reorganización del poblamiento bajomedieval en el territorio de la Comunidad de aldeas de Daroca» (Iranzo y Ortega, 2011: 67-126). La atención dispensada al tema en números recientes de esta misma publicación (Allué, 2018: 25-68; Allué y Rodrigo-Estevan, 2019:137) y la necesidad de precisar los datos ofrecidos en el anterior trabajo, una posibilidad que se desprende de este pequeño hallazgo, me inducen a ofrecer una nueva transcripción de la carta de población de Lagunas y del resto de los lugares, esta vez sobre un traslado coetáneo, mucho más próximo al original y no alterado por la transmisión documental y las intervenciones de los escribanos dieciochescos de la Audiencia, así como a añadir algunos comentarios sobre la compleja situación del despoblado de Lagunas en el transcurso del siglo XV, a partir de las transacciones de las que fueron objeto sus rentas eclesiásticas. ${ }^{2}$ Todo ello en aras a una mejor comunicación científica de un material que nos sigue pareciendo fundamental para explicar cuándo y cómo se alcanza el momento álgido de la población y de la ocupación del espacio en el Aragón de la plena Edad Media, así como aspectos concretos del deterioro de las rentas señoriales y de la continuidad de la actividad agraria en sectores periféricos de ese mismo espacio.

\section{La estratégica iniciativa de la Comunidad de aldeas de Daroca}

Recordemos brevemente que el artículo precedente estaba dedicado a la respuesta articulada por la Comunidad de aldeas de Daroca con el objetivo de paliar los problemas derivados del crecimiento demográfico que había experimentado durante la etapa de expansión agraria, una respuesta pareja a la creciente demanda de los mercados cerealistas, mediante la determinación de

1 Este trabajo se integra en las líneas de investigación del Grupo de Investigación de Referencia CEMA, reconocido por el Gobierno de Aragón.

2 Archivo Histórico Provincial de Zaragoza AHPZ-J-012276/1. Aprehensión del monasterio de Santa Fe contra bienes de la ermita de Nuestra Señora de Lagunas sitos en Cariñena respecto al derecho a percibir las décimas. Diez piezas. 1725-1793. 
poner en explotación zonas marginales de las comarcas del Campo de Cariñena y Sierra Menera, un ambicioso intento de colonización en los vértices extremos, al norte y sur de la extensa región bajo su control. Esta iniciativa se resolvió en un ensayo de reordenación de las franjas montañosas ibéricas en las que persistía todavía cierta inestabilidad social, derivada de su trayectoria como tierras de frontera. En este sentido, el proyecto que materializó la Comunidad de aldeas de Daroca en su plega de la primavera de 1316 afectaba a Lagunas, Peracense y Almohaja. Bastante distantes entre sí, estas tres localidades, no sin experiencias pobladoras previas, compartían el carácter marginal de las tierras parcialmente lacustres aptas para ser puestas en cultivo por los campesinos asentados en ellas. Los sesmeros encargados de llevar a término el proceso colonizador tenían el mandato de proceder a la delimitación de los respectivos términos mediante mojones, el reparto de tierras en lotes (quiñones) y la puesta en explotación de los enclaves citados. La tarea de agrimensores se extendía a la agrupación de parcelas de cultivo para dar forma a explotaciones denominadas cabomasos, al frente de los cuales había hombres y mujeres que constituían unidades económicas y fiscales familiares. El equipamiento del cabomaso se completaba con el derecho a construir la vivienda propia y con la participación en los recursos naturales: dehesa de leña, pastos y cotos de caza, además del horno concejil cuyo uso era obligatorio y excluyente. Todos esos derechos estaban estipulados y reconocidos en el 'estatuto' o privilegio de los aldeanos de la Comunidad de aldeas.

La edición y estudio de la carta puebla de Lagunas, hasta entonces inédita, nos permitió analizar la plasmación práctica de procesos históricos que manifiestan una clara tendencia hacia la disciplina social, observable en tres aspectos: la configuración de hábitats agrupados, la realización de repartos organizados de tierras y la profunda agrarización de las comunidades que, hasta entonces, habían encontrado su nicho productivo en la ganadería, la explotación minera y un agreste bandidaje. De esta forma, mejoraba nuestro conocimiento sobre las dinámicas sociales en las Comunidades de aldeas de Aragón en la tardía Edad Media.

Lagunas, equidistante de Alfamén, Cosuenda y Longares y muy próximo a Cariñena, se hallaba inserto en el ámbito señorial de los primitivos monasterios cistercienses de Lagata y Juncería desde finales del siglo XII, a partir de donaciones de nobles locales y merced a los privilegios y exenciones concedidos a los monjes por las autoridades eclesiásticas. A finales de esa centuria, Lagunas llegó a constituir un núcleo de población con suficiente entidad e identidad 
propia; sin embargo, el monasterio de Rueda, heredero de los anteriores cenobios, se deshizo de sus intereses en esta zona para reorientarlos hacia el bajo Ebro, dejando Lagunas a merced de las apetencias de linajes nobiliarios más o menos favorecidos por las instancias reales. Resultado de esta tortuosa senda de dominio señorial, la Comunidad de aldeas de Daroca obtuvo de Jaime II la facultad de disponer de las primicias de Cariñena por un plazo de seis años para comprar el lugar de Lagunas al noble Sancho de Orta, en 1293. A partir de ahí se desplegaron las iniciativas de puesta en explotación y reactivación del poblamiento que hemos resumido (Iranzo y Ortega, 2011: 69-87).

La edición del texto de la carta de población de Lagunas a partir, como decimos, del traslado notarial —un pergamino coetáneo al original—, permite precisar detalles de cierto interés a lo anteriormente expuesto. El primero de ellos es que la plega del Común de las aldeas del 15 de marzo de 1316 en la que se adoptaron las estratégicas decisiones de amojonar y hacer lotes en lugares baldíos de su periferia - Almohaja, Peracense y Lagunas - no tuvo lugar en la iglesia de san Julián de Lagunas, que no existía entonces, sino en la de San Valentín de Báguena, según podemos leer en el pergamino. No es un punto baladí en absoluto, pues la existencia histórica de la iglesia es como la «partida de bautismo» del lugar, ya que se trata de la sede donde radicarán los derechos eclesiásticos que veremos rentabilizar en las centurias posteriores. Pero lo cierto es que a principios del siglo XIV no existía y, de hecho, el primer punto de la carta puebla de Lagunas está dedicado a resolver la ausencia de iglesia y cementerio en la nueva población, asignando a tales efectos las casas y el corral próximo a las mismas de Bartolomé de Eslava. La lectura correcta de los nombres de los pobladores, como este Bartolomé Eslava, permite perfilar mejor las líneas de parentesco que se pueden advertir al repasar la antroponimia: así, cobra su nombre la mujer de Juan Moreno, doña Oria (Donhoria), el apellido Lizana deviene Licena y Domingo recibe el epónimo correcto de Dona Gila. Igualmente ha sido posible, gracias a la lectura sobre el original, dotar de contenido a la taula de la Comunidad de aldeas: la mesa del recaudador de la hacienda del Común donde los veinticuatro pobladores de Lagunas, y los dieciséis que llegaran hasta completar las 40 unidades planificadas, debían entregar los censos previstos y nada pequeños — 100 sueldos al año cada unidad fiscal — que debían por el disfrute de tierra y vivienda y su derecho a participar en el aprovechamiento de los comunales: la leña, caza y herbaje en la dehesa de La Matilla, además de recibir otros servicios, entre los cuales destaca el horno concejil. 


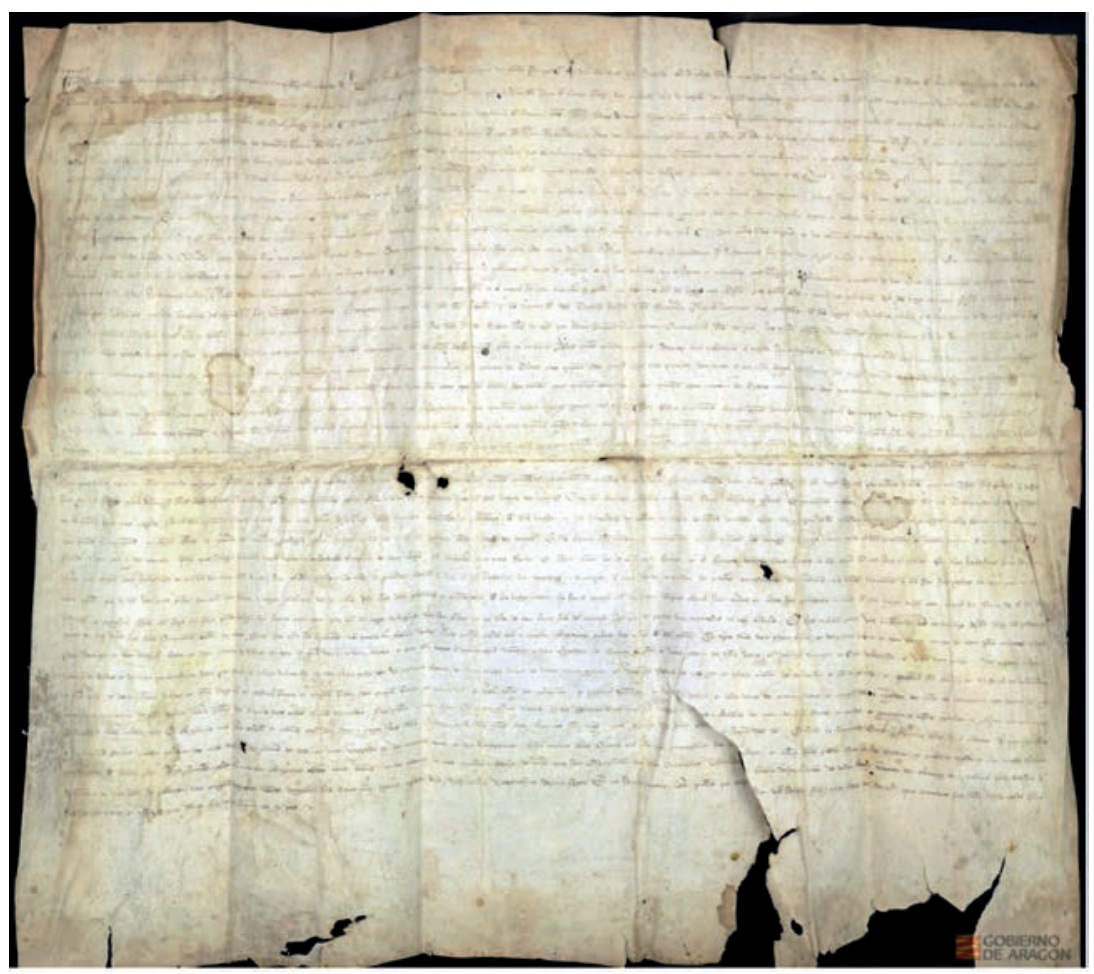

Figura 1. Carta de población de Lagunas. AHPZ-C-PERGAMINOS-000084/04

En este caso concreto, por otra parte, no es menor el interés filológico que tiene la transcripción a partir del original de la carta puebla de Lagunas (1316) para el conocimiento la lengua aragonesa. Señalaré solamente que en la transcripción moderna se advierte el cambio de et por $y$; del grupo $n y$ por la ñ, la $x$ por $j$ y las $f$ por $h$, que hay hipercorrección gráfica, como 'ordenamos' en vez de hordenamos; 'haber' por aver, y se omiten las terminaciones en $t$ (segunt, primerament); por último se sustituyen términos desconocidos: plega de san Miguel pasa a ser fiesta de san Miguel. Y así otros muchos ejemplos, que se extienden a términos de difícil lectura e interpretación plausible como siesto que el escribano del siglo XVIII proponía transcribir como fiesto y yo entendí como 'fructo', ofreciendo una aproximación semántica. ${ }^{3}$ Esta utilidad del tex-

3 Agradezco a Guillermo Tomás su ayuda con las cuestiones relativas al aragonés. 
to antiguo incide en la valoración del mismo proceso de transmisión documental: en 2011 ofrecimos la transcripción efectuada por el escribano de Cámara de la Audiencia a partir del mismo pergamino, la cual fue posteriormente corregida por un perito en letra antigua, Benito Ariño. La consulta directa del original ha permitido constatar que el tal perito lo era ciertamente y que apuntó con acierto las desviaciones del tenor literal que manifestaba la transcripción del escribano. [Figura 1]

\section{Una nueva perspectiva señorial}

Hasta aquí, las aportaciones que supone el hallazgo del pergamino del siglo XIV y sus valores textuales asociados. Pero son las copias de otros cinco pergaminos incluidos en el dosier documental que aportó el monasterio de Santa Fe de Zaragoza al pleito sobre su derecho a percibir las décimas de Lagunas los que nos abren una nueva perspectiva para comprender mejor los beneficios producidos por las rentas eclesiásticas durante el periodo bajomedieval. Gracias a ellos, observamos que el fracaso poblacional de Lagunas no se tradujo en el abandono de las tierras, que mantuvieron una rentabilidad económica suficiente como para ser objeto de apetencias y transacciones durante todo el siglo $\mathrm{XV}$ y, a pesar de no haber renovado nunca la experiencia de la formación de un núcleo habitado, merecer pleitear por ello durante los tres siglos de la Modernidad. De hecho, fueron las décimas el problema de fondo que se arrastró durante cuatrocientos años hasta convertirse en el argumento esencial del pleito, en diez piezas, que el monasterio de Santa Fe llevó ante la Real Audiencia en 1725, en el cual se copiaron ocho documentos medievales aportados como pruebas. [Figura 2]

Las copias de la documentación medieval aportada por el monasterio de Santa Fe se presentaron en un volumen encuadernado en pergamino que formaba parte de la tercera pieza del largo pleito (1725-1793), donde le corresponden las páginas 56 a 92, de los más de 3000 folios de que consta. Es el acta notarial de varios pergaminos que mostró ante el tribunal fray Bernardo de Miravete, procurador del monasterio, acta formalizada por el notario apostólico Pedro Borau de Latrás, que los certificó como auténticos «y sin sospecha de alteración» (lo que sugiere que tales alteraciones no eran infrecuentes), aunque, por su antigüedad, se le había solicitado que sacase copias. Esa cautela por la antigüedad de los documentos, que indujo a copiarlos, no se mantuvo respecto a la carta de población de Lagunas, un pergamino marcado en su 


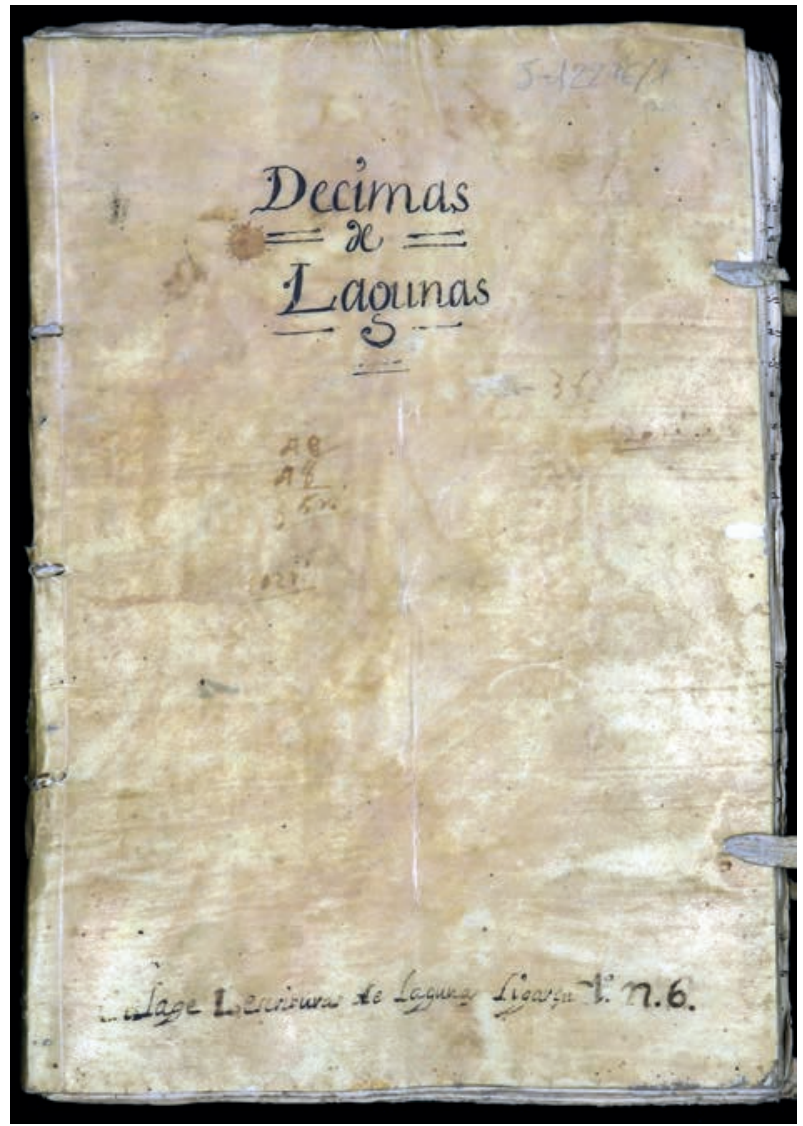

Figura 2. AHPZ-J-012276/1. 1725-1793. Cuadernillo inserto en la pieza 3a

reverso como prueba $\mathrm{n}^{\circ} 1$, que debió de ser insertado como anexo en la misma tercera pieza del pleito. Al final del expediente, ya con papel sellado del año 1793, hay una certificación del perito jurado ya citado, que, a la vista de los originales, corrigió las lecturas tanto de la carta de población exenta como los textos de los restantes documentos medievales (exceptuando un privilegio real de Jaime I del año 1225 referido a la permuta de bienes en Pina hecha con el monasterio de Rueda por los lugares de Lagunas, Aylés y Jaulín). ${ }^{4}$

4 Escrito con letra bastante diferente de las copias citadas, se encuentra en un folio adherido, y no cosido al cuadernillo que se incluye al final del dosier. 
Los dos primeros documentos copiados en el volumen de pruebas aportadas por los cistercienses de Santa Fe son bien conocidos: la donación del obispo de Zaragoza, Pedro de Torroja, en 1178, de todas las décimas y primicias de los lugares de Aylés y Lagunas al monasterio cisterciense de Juncería, antecesor de Santa María de Rueda. Este texto era el origen del derecho reconocido al monasterio sobre las rentas eclesiásticas (excepto de las nuevas roturaciones: novalibus). El segundo texto es la cesión de los derechos y frutos de las iglesias de Aylés y Lagunas a Pedro Jiménez de Rada, arcediano de Daroca, en cuya circunscripción se hallaban. Esta cesión de las rentas de Lagunas hecha en 1290 por el abad de Rueda a cambio de dos áureos alfonsinos, por dos años, nos indica algunas evidencias. En primer lugar, que el terreno de Lagunas estaba siendo aprovechado con éxito a finales del siglo XIII y, además, que su explotación generaba los suficientes beneficios para que, en 1316 la Comunidad de aldeas de Daroca, con dominio jurisdiccional sobre este espacio, decidiera llevar a cabo una puebla. Debido a una confluencia de diversos motivos, entre los que hay que señalar como más inmediato el castigo sufrido en la zona durante la guerra de los Dos Pedros, las crisis demográficas y epidemias subsiguientes así como otras dificultades, el cuidadoso proyecto de poblamiento de Lagunas finalmente no cumplió las expectativas, pues la partida quedó reducida a un poblamiento intercalar de muy débiles dimensiones.

El escenario se traslada a continuación a la época de dificultades tardomedieval y su incidencia en las instituciones eclesiásticas, situación de crisis que se vio agravada en los primeros decenios del siglo XV por el Cisma de Occidente. Los monasterios cistercienses radicados en Aragón se lanzaron a una reordenación de sus señoríos y rentas, para lo cual precisaban la autorización papal. Benedicto XIII, por su parte, con el apoyo del rey Fernando I, había nombrado a los nuevos abades de Santa Fe, Santa María de Rueda y Santa María de Piedra en el otoño de 1413 (Cuella, 2006: 281, 282 y 283). En un panorama de penuria que se describe de forma poco halagüeña, los abades de Veruela y Santa Fe — Antonio de Jijona y Antonio Julián respectivamente-, fueron comisionados por Benedicto XIII para organizar las finanzas aragonesas de la orden, con autorización para enajenar propiedades y endeudarse. Sin embargo, el papa rechazó algunas de las operaciones que realizaron al amparo de bulas anteriores. Esto sucedía en diciembre de 1413; para entonces, Santa María de Rueda, que había vendido el lugar de Codo, vio revocado el acuerdo, recibiendo a cambio del permiso papal para hacerse con recursos hasta la suma de 12.000 florines mediante la venta de otras localidades, granjas o ren- 
tas «e incluso de los mismos diezmos, censos, tributos y derechos pertenecientes al monasterio, pero en realidad de poca utilidad o provecho para la comunidad» (Cuella, 2006: 294).

Así las cosas, el abad y el convento rotense delegaron en su procurador Miguel de Sesas para negociar la venta de Esteruelas (en el municipio de Perdiguera) y Lagunas, así como otras rentas en Zaragoza y sus términos, en Zuera, Fuentes de Ebro, Leciñena, Utebo, Calatorao y Alcañiz. Todos, excepto Fuentes, eran lugares relativamente alejados del monasterio cisterciense que estaba por entonces, como se ha dicho, reordenando la explotación de sus señoríos. En esta pieza del conjunto documental recién hallado se describe la desoladora situación del monasterio de Santa María de Rueda, sumido en la penuria, que finalmente consigue vender una renta anquilosada, proporcionándonos un dato que nos podría ser útil para calibrar el nivel de éxito alcanzado por el esfuerzo repoblador de la Comunidad de aldeas de Daroca había desplegado un centenar de años antes. El texto refleja los efectos sufridos en Lagunas por la mortaldad y por las guerras, en alusión a los padecimientos de la comarca de Cariñena en la segunda mitad del siglo XIV y primeros decenios del XV, de tal manera que las casas de los 40 pobladores estaban en total ruina y apenas lograban obtener un centenar de sueldos anuales de los diezmos y todos los derechos que el abad y los monjes tenían en Lagunas. Recordemos que la carta de población estipulaba esos mismos 100 sueldos como censo anual para cada nuevo hogar de los establecidos. Por fin, los monjes encontraron una oferta satisfactoria, la que formuló un mercader de Zaragoza, Pedro Gil de Villarreal, juntamente con su mujer Sancha de Anguas, que ofrecieron 50 florines, una cantidad equivalente a unos 550 sueldos, para pasar a ser reconocidos como «verdaderos señores» de las décimas y otros derechos no especificados. El contrato se firmó ante el notario Martín de Tarba el 13 de mayo de 1414, y un mes más tarde los vendedores dispusieron como fianza el lugar de Romana, entre Escatrón y Samper de Calanda.

A la búsqueda de una confirmación externa de la validez y cláusulas específicas de esta compraventa, he consultado los protocolos de Martín de Tarba, pero lamentablemente el registro de ese año está muy fragmentado y mermado en los años entre 1411 y 1415, quedando apenas unos folios del protocolo de 1414, cuyo índice, por otra parte, no conserva mención alguna a esa transacción. Sin embargo, el negocio del monasterio de Santa María de Rueda con el arrendamiento por tres años del castillo y lugar de Codo sí que se conserva en 
el protocolo del notario Martín de Tarba y puede servir para dar una idea de los matices de este tipo de gestión de las rentas eclesiásticas que estaban haciendo entonces los cistercienses. Así, los monjes acordaron con Ferrando de Arcos, escudero de Belchite (localidad cuyo término municipal englobaba el de Codo), el arrendamiento por tres años de los derechos señoriales de Codo (parece que exceptuados los eclesiásticos, aunque Codo era un lugar de poblamiento mudéjar) a cambio de 9.000 sueldos, con el compromiso de que el arrendador liberase al concejo de un censal de 7.000 sueldos jaqueses (que tenía un interés anual de 700 sueldos) que la población había contratado en otro tiempo probablemente para pagar una deuda del monasterio y, una vez abonada esta cantidad cediera el arriendo de Codo a otro mercader, Francesc Riera, que lo conservaría en comanda, es decir, como parte de otra deuda distinta contraída con él por parte de Santa María de Rueda. ${ }^{5}$ En otras palabras, durante tres años, Fernando de Arcos liberaba las rentas monásticas sobre Codo de un censal que las tenía completamente enajenadas, para después ceder el arrendamiento a Francesc Riera, que había hecho otro préstamo a la comunidad.

El monasterio de Santa Fe, próximo a Zaragoza y situado en el mismo valle del Huerva que bordea la tierra de Cariñena recuperó las décimas de Lagunas para la orden cisterciense, pues en los días finales del año 1430 las recompró a Gil Pérez de Villarreal y Sancha de Anguas, pagando 8.500 sueldos jaqueses. Se conserva el contrato barrado en el protocolo de Pedro Serrano. ${ }^{6}$ Por el registro documental del pleito, sabemos que fue fiador de esta transacción su propio hijo, del mismo nombre, Gil Pérez de Villarreal menor, mientras que los testigos eran dos hombres ilustres de la ciudad, que compartían con Pérez de Villarreal la cofradía de mercaderes Juan de Mur, mercader, y Alfonso de Mur, jurista y lugarteniente del Justicia (Falcón, 1997: 455-456). Si lo vemos en términos de negocio, Pérez de Villarreal había invertido algo menos de 550 sueldos en 1414 para, en el plazo de 15 años, obtener un beneficio neto de 8.000 más, aprovechando una época de mejoría en los flujos económicos y rentabilizando el interés del comprador por la recuperación de unas rentas que seguramente se habían convertido en bastante estables.

5 Archivo Histórico del Colegio de Notarios de Zaragoza (APNZ), n 1350. El arrendamiento de Codo, ff. 53-71.

6 APNZ, n ${ }^{\circ} 2074$, Pedro Serrano, 1428-1430, ff.262r-v 


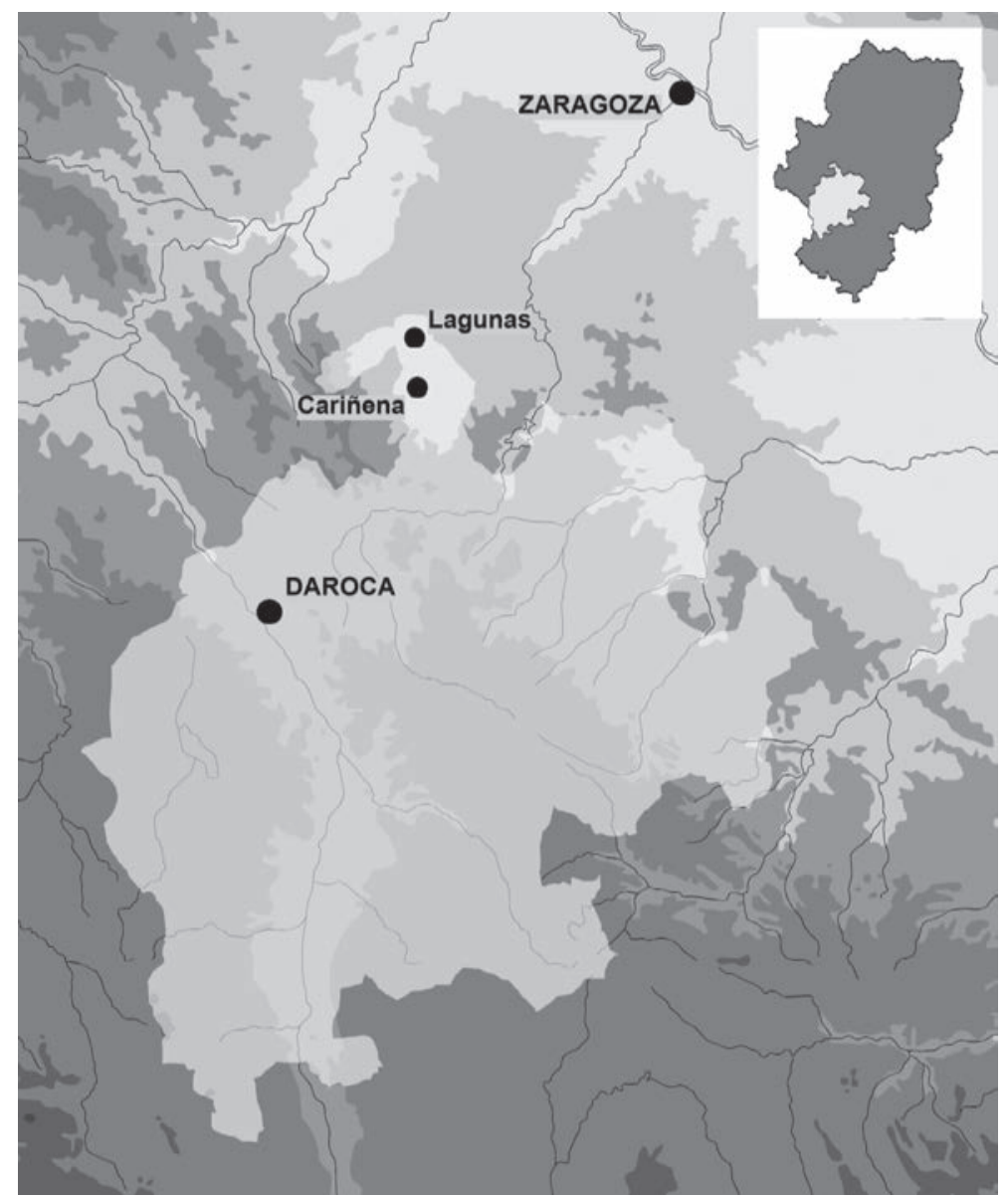

Fig. 3: Mapa de la Comunidad de Aldeas de Daroca.(Julián M. Ortega)

Para entender mejor las estrategias que guiaban la gestión del dominio del monasterio de Santa Fe, resulta muy útil la consulta del Registro general del archivo, editado por Giménez Ferreruela, que permite seguir la intrincada senda de entrada y salida de estas rentas en el patrimonio del monasterio, aunque el editor interpreta que, durante los siglos medievales, se trataba de la propiedad sobre estos lugares (Giménez, 2012: 23). La localidad de Lagunas tenía asignadas en el archivo monástico dos ligarzas en exclusiva, la $1^{\mathrm{a}}$ y $2^{\mathrm{a}}$ del cajón $\mathrm{L}$ (signaturas visibles en el volumen estudiado: Figura 2). Siguiendo la ordenación 
del Registro general del archivo, Lagunas compartía la ligarza $3^{\text {a }}$ con la población de Cariñena, lo que sirve como indicativo de la deriva que tomó la absorción de esta pardina exactamente hasta los años finales del siglo XVIII recogidos en el pleito de la Real Audiencia que estamos analizando, del cual también se conservaba copia. Por lo demás, todos los documentos aportados en el pleito aparecen reflejados en el inventario del archivo, con lo que la deriva de las rentas decimales de Lagunas que hemos expuesto resulta confirmada. Con alguna variación importante, para ser precisos, pues el importe de la primera venta, en 1414, no se lee como 50 florines, sino el doble de esa cantidad, mientras que aparece reducido a 425 sueldos el precio de 8.500 sueldos pagado por Santa $\mathrm{Fe}$ en la reventa de estas rentas a Pérez de Villarreal en 1430, que conocemos también por el protocolo de Martín de Tarba (Giménez, 2012: 178-179).

En todo caso, como se ha dicho, el Registro general del archivo nos permite conocer la conservación de este conjunto de documentos medievales (e incluso de la certificación notarial de los mismos aportada al pleito) así como discernir la implicación y el beneficio que obtuvo la villa de Cariñena en todo este negocio de puesta en explotación del terreno semipantanoso que había desecado y repartido en lotes, pues los contratos de arrendamientos de tierras y compraventas en la zona son capitalizados por los vecinos de Cariñena, entre los que hallamos a lo largo del tramo final del siglo XV los mismos nombres de los primeros quiñoneros: Juan de Oria y Domingo de Álava, entre otros (Giménez, 2012: 181-187). Sin dejar de lado la utilidad de esas tierras marginales para la cabaña ganadera de la Comunidad de aldeas (Iranzo y Ortega, 2011: 88-89). El aprovechamiento agrícola y ganadero se extendió hasta los años finales del siglo XVIII, cuando los vecinos de Cariñena seguían escaliando las tierras del paraje de Lagunas.

\section{Conclusión}

Si la aventura de la Comunidad de aldeas de Daroca de desecar y poner en explotación la llanada de Lagunas terminó como un fracaso poblacional, desde el punto de vista del beneficio a largo plazo esta actuación resultó rentable tanto para las instituciones eclesiásticas implicadas y los agentes económicos como para el concejo de Cariñena, que había apostado parte de sus ingresos por la recuperación de esos espacios agrícolas, una enorme partida que acabó integrando en su término municipal en apenas un centenar de años (Iranzo y Ortega, 2011: 78 y 85). 


\section{Apéndice documental}

1316, abril-mayo

Carta de población de Lagunas, resultado del acuerdo de la Comunidad de aldeas de Daroca de poner en explotación los terrenos de Almohaja, Peracense y Lagunas.

-AHPZ, Pergaminos, Carp. 84, $\mathrm{n}^{\mathrm{o}}$ 4. Procede de Real Audiencia, $\mathrm{J}-12276 / 1$.

Aqueste yes translat bien e fielment sacado de un privilegio siquiere carta publica de la poblacion de Lagunas, de Almoffaja e de Petraselz, el qual se sigue dius aquesta forma:

In Dey nomine et eius gratia. Conoscida cosa sia a todos homes como nos don Domingo Blasco de Barrachina, sesmero de la sesma del Rio de Barrachina, don Aznar de Lechon, sesmero de la sesma de la Trasierra, don Beneyto Negro, sesmero de la sesma del Rio de Xiloca, Lazaro Perez, sesmero de la sesma del Campo de Gallocanta, Domingo Pascual, sesmero de la sesma del Campo de Langa, don Per Alvarez, vezino de Baguena, don Miguel de Collados, vezino de Quenquabuena, por el poder a nos dado por la universidat de las aldeas de Darocha con carta publica feyta por mano de Sancho Maynar, notario publico, de la qual el tenor yes a tal:

«Conoscida cosa sia a todos homes como nos los homes del Comun de las [raspado] aldeas de Daroca, plegados en plega en la eglesia de San Balantin de Baguena, por carta de Jorge Martinez de la Torre, notario de las ditas aldeas de Darocha, damos et otorgamos licencia e poder siquiere actoridat a vos, Domingo Blasco de Barrachina, sesmero de la sesma del Rio de Barrachina, et a vos don Aznar de Lechon, sesmero de la sesma de la Trasierra, et a vos don Beneyto Negro, sesmero de la sesma del Rio de Xiloca, et a vos Lazaro Perez, sesmero de la sesma del Campo de Gallocanta, et a vos Domingo Pascual, sesmero de la sesma del Campo de Langa, et a vos don Per Alvarez, vecino de Baguena, et a vos don Miguel de Collados, vecino de Quenquabuena, que vos, en nombre et en voz nuestra podades departir, quinyonar, mojonar, encara poner en siesto et en estado los lugares de Pieraselz, d'Almofaja et de Lagunas et los terminos de aquellos et de cada un lugar de aquellos segunt que a vos mejor visto sera, et encara a los ditos pueblos et pobladores que en los ditos lugares ponredes o asignaredes, dar deffesas de montes et de herbages et de chaca o de qualquiere cosa que los ditos pueblos et pobladores de aquellos 
sera necesario de aver, que los podades fer, ordenar et firmar en siesto o en estado poner, segunt que nos dito Comun fariamos o fer podriamos, dando a vos pleno et general poder ad especial administracion et poderio sobre las avantditas cosas et cada una de aquellas a mision et costa de nos dito Comun, et en aquel siesto et en aquel estado que vos los ditos lugares et los terminos de aquellos ponredes o asentaredes, nos los homes del dito comun lo prometemos aver por firme et perdurable agora et a todos tiempos jamas.

Porque luego encontinent mandamos al dito Jorge Martinez, escribano, el qual yes present, que a vos de mesion aquella que avreis menester demientre que'n los ditos lugares e en los terminos de aquellos estaredes en siesto e en estado poner. Pero que los ditos lugares et los terminos de aquellos et de cada un lugar de aquellos pongades en siesto et en stado fasta la fiesta de Casimodo primera vinidera, si no que pechedes a nos, dito Comun, cien maravedis de pena alfonsis.

Facta carta ydius marcii anno millesimo trecentesimo quintodecimo.

Testimonios son desto don Miguel Juffre et Pero Garcia et Miguel d' Alava, notario.

Et yo, Sancho Maynar, notario publico por el senyor rey en las aldeas de Daroca, aquesta carta fiz et mi signo y pus».

Hordenamos et establimos la poblacion del lugar de Lagunas et de sus terminos dius forma et condiciones que se siguen:

I. Primerament, a reverencia de Dios, que es comencamiento et fazedor de todos los bienes et obras desti mundo, hordenamos que las \casas/ que fueron de don Bertholomeu d' Eslava, sitiadas en el dito lugar de Lagunas, sian pora eglesia et el corral sia pora ciminterio de aquella, por razon que en el dito lugar no a eglesia, las quales casas e corral los pobladores del dito lugar ayan pora eglesia e ciminterio a todos tiempos.

II. Item hordenamos que todo el termino de Lagunas sia feyto quaranta quinyones, exceptado el lugar que yes dito de La Matilla, que yes dentro del dito termino, segunt que yes affrontado, el qual lexamos a los pobladores del dito lugar, que sea deffesa de lenya, de herbages et de caca, segunt el privilegio de los aldeanos de las ditas aldeas.

III. Et de cada uno destos quaranta quinyones que seran, den et paguen al dito Comun de las ditas aldeas cient solidos jaqueses por cada un 
quinyon, que montan quatro mille solidos de jaques, los quales paguen et sean tenidos pagar al conto primero de san Miguel, que sera fecho por el Comun de las ditas aldeas, la meytat, es a saber, dos mille solidos jaqueses et los otros dos mille solidos jaqueses romanientes, de la dita plega de san Miguel primera en un anyo.

IV. De los quales quaranta quinyones damos a los pobladores que agora son en Lagunas los vint e quatro, es a saber: a don Pero Simon, un quinyon; a dona Maria Licena, otro quinyon; a Donhoria, muller de don Johan Moreno, otro quinyon; a don Pero Domingo, otro quinyon; a don Miguel Royo, otro quinyon; a don Martin de Codos, otro quinyon; a don Miguel d'Oria, otro quinyon; a don Lazaro de don Johan Lazaro, otro quinyon; a don Miguel Domingo, otro quinyon; a don Esperandeu, otro quinyon; a Ramon Guillem, otro quinyon; a Maria don Johan d'Oria, otro quinyon; a Domingo Donagila, otro quinyon; a Garcia Valconchan, otro quinyon; a Vicent don Ximeno, otro quinyon; a don Cebrian, otro quinyon; a don Martin de Codos, otro quinyon; a don Per Arnalt, otro quinyon; a Domingo Per Arnalt, otro quinyon; a Pero Valconchan, otro quinyon; a don Pero Perez, otro quinyon; a don Aparicio Romeu, otro quinyon; a doña Menga Licena, otro quinyon; a dona Menga Gayan, otro quinyon.

V. Et los setze quinyones romanientes, damos a Domingo Pascual de Mengot un quinyon; a Pero Matheu de Valconchan, otro quinyon; a Johan de Pelarda, otro quinyon; a Pascual de La Almunia, otro quinyon; a Pascual de Valconchan, otro quinyon; a Johan Polo, otro quinyon; a Johan de Alava, otro quinyon; a Johan d'Aguaron, otro quinyon; a Pascual Ferriz, otro quinyon; a Miguel, fillo don Miguel Ferriz, otro quinyon; a Pero Val, otro quinyon; a don Johan de Valconchan, otro quinyon; a Pascual de Arandiga, otro quinyon; a don Johan d'Alava, otro quinyon; a Johan Doria de don Martin Doria, otro quinyon; a Johan de Cariñena, lotro quinyon/, pagando por cada un quinyon la dita quantia en cada uno de los terminos a la taula de los ditos aldeanos.

VI. Item que los ditos pobladores que agora son, de gracia especial ayan por lures moradas aquellas casas que agora moran, de [roto: mexora de los pobladores que agora vendran], por razon que la compra del dito lugar [roto: de Lagunas] et de aquella ora entaca continuament y an morado. 
VII. Et los otros setze pobladores que y venran fagan lures moradas et tomen solar pora casas cerca de aquellas que y son en lugar suficient, las quales quales ( sic) casas et moradas fagan dentro [roto: del quinyon et morada] en adelant moren en aquellas continuament, en aquellas fendo residencia personal et teniendo cabomas, pechando al dito lugar de Lagunas por aquellos bienes que y avra, segunt de las puestas que visto sera por la plega general de san Miguel de las ditas aldeas.

VIII. Que todos los \ditos/ quaranta quinyones pechar podran et aun aquellos pobladores que en el dito lugar de Lagunas qui no reciben o recibran et alli no faran residencia personal continuament ni ternan cabomas, segunt dito yes, que pierda el dito quinyon et la quantia que $\mathrm{y}$ avra pagado et el dito quinyon finque al Comun de las ditas aldeas.

IX. Item que los ditos quaranta quinyones et pobladores del dito lugar ni los succesores de aquellos ni alguno de aquellos en algun tiempo non puedan vender ni vendan, ni empenyar ni en alguna manera alienar ni dar [ilegible: a labor] los ditos quinyones ni alguno dellos ni partida de aquellos ad alguna persona estranya que non sea vezino ni pechero de las aldeas de Daroca. E si lo faziere, aquella vendicion o empenyamiento o allenamiento no tenga ni valga, ante pierda el dito quinyon et sia tenido pechar cient maravedis alfonsis de pena pora el dito Comun.

$\mathrm{X}$. Item que si algun quinyonero terna barbecho o sembrado el quinyon de otro alguno, que'l sembrado que avra fecho esti present anyo, sea de aquel qui lo sembro et el fruyto levantado, que finque la tierra ad aquel cuyo sera el quinyon. E de los barbechos que y son fechos, que alguno avra barbechado en quinyon de otro, aquel de qui sera el dito quinyon sea tenido de emendar ad aquel que fizo el dito barbecho las juvadas e la mesion que avra fecho o emendarle en dineros a conoscimiento de lavradores e de buenos homnes que no sian suspechos a la una part ni a la otra, aquello que la dita $1 \mathrm{a}<\mathrm{b}>$ or avra puesto ho qu' 1 dexe senbrar e coger el fruyto de un anyo.

XI. Item que los ditos pobladores et quinyoneros del dito lugar puedan fer forno concejal en el dito lugar de Lagunas, al qual sean tenidos yr todos los pobladores e vezinos del dito lugar a cozer pan, el qual dito forno sea del dito concejo et otra persona alguna non faga nin fazer pueda en algun tiempo forno pora cozer pan en el dito lugar de Lagu- 
nas nin sian osados yr ni usar de otro forno sino del concejal, dius pena de pechar diez maravedis de oro alfonsis.

Et nos ni el dito Comun, vos cumpliendo las condiciones de suso ditas, no podamos a vos ni a los vuestros los ditos quinyones toller ni a otras personas dar; et si lo fizieremos, non pueda aver alguna valor.

A las quales cosas tener e complir obligamos todos los bienes del dito Comun.

Et nos ditos don Pero Simon et dona Maria Licena et Donhoria, mujer de don Johan Moreno, et don Pero Domingo et don Miguel Royo et don Martin de Codos et don Miguel d'Oria et don Lazaro de don Johan Lazaro et don Miguel Domingo et don Esperandeu et Ramon Guillem et dona Maria de Johan d'Oria et Domingo Donagila et Garcia Valconchan et Vicent don Ximeno et don Cibrian et don Martin de Codos et Domingo Perarnalt et don Per Arnalt et Pero Valconchan et don Pedro Perez et don Aparicio Romeo et dona Menga Licena et dona Maria Gayan et Domingo Pascual de Mengot et Pero Matheu de Valconchan et Johan de Pelarda et Pascual de La Almunia et Pascual de Valconchan et Johan de Polo, dona Johana d'Alava et Johan d'Aguaron et Pascual Ferrer, et Miguel, fillo don Miguel Ferriz, et Pero Val et don Johan Valconchan et Pasqual d'Arandiga et don Johan d'Alava et Johan d'Oria de Martin d'Oria et Miguel d'Alaba, procurador de Johan de Carinyena, con carta de procuracion feyta por mano de Johan d'Alaba, notario publico, scripta a quinquo dias entrant el mes noviembre era millesima trecentesima quinquagesima tercia, la dita poblacion recevimos dius la forma et penas et condiciones de part de suso scriptas et notadas, et prometemos aquellas guardar et observar por nos et por omnes succesores nuestros a todos tiempos, et obligamos nos todos ensemble et cada uno por el otro dar et pagar los ditos quatro mille solidos jaqueses a los terminos sobre ditos en la taula de los ditos aldeanos, segunt dito yes.

Et si no lo fazieremos, que el escribano de las ditas aldeas que por tiempo sera o los hombres suyos puedan prendrar de nuestros bienes et de cada uno de nos en una vegada o en muchas tanto et tan largament fasta que los ditos quatro mil solidos jaqueses intregrament sian pagados o aquellos bienes puedan pendrar et facer pendrar et puedan vender o fer vender asi como pena o pecha del senyor rey.

A las quales cosas tener et conplir obligamos todos nuestros bienes et de cada uno de nos, mobles et rayzes doquiere que sean, especialment los ditos quinyones. 
Testimonios fueron desto presentes don Andreu Adan, rector de Alcanyz, et Pascual Perez, capellan de Carinyena, et don Lorent de Galbeion, don Miguel d'Aguilon, vezinos d'Aguaron.

Feyta carta IIII ${ }^{\mathrm{a}}$ nonas aprilis anno Domini millessimo trecentesimo decimo sexto.

Et yo, Sancho Maynar, notario publico por actoridat del senyor rey en las aldeas de Daroca, que en todas las sobreditas cosas present fue et me acerie, et aquesta carta scribir fiz et mi sig(signo)no hi pus.

\section{Referencias bibliográficas}

ALLUÉ ANDRÉS, Lidia (2018) «Dinámicas de poblamiento y población en un espacio de frontera: la Comunidad de Aldeas de Daroca (siglos XIII-XV)», Aragón en la Edad Media, 29: 25-68.

AlLuÉ ANDrÉs, Lidia C. y Rodrigo-Estevan, María Luz (2019) «Dehesas antiguas, pastores foranos y jurisdicciones cuestionadas: conlictividad ganadera a finales de la Edad Media en la Comunidad de Aldeas de Daroca», Aragón en la Edad Media, 30: 121-142.

CONTEl BAREA, Concepción (1977) El Císter zaragozano en el siglo XII: abadias predecesoras de Nuestra Señora de Rueda de Ebro. II. Zaragoza, Institución Fernando El Católico.

Cuella Esteban, Ovidio (2006) Bulario aragonés de Benedicto XIII. Vol. III. La Curia de Peñíscola (1412-1423). Zaragoza, Institución Fernando El Católico.

FALCÓN PÉREZ, María Isabel, ed. (1997) Ordenanzas y otros documentos complementarios relativos a las corporaciones de oficio en el reino de Aragón en la Edad Media. Zaragoza, Institución Fernando El Católico.

GIMÉNEZ FERRERUELA, Héctor, ed. (2012) El registro general del archivo del real monasterio de Santa Fe (Zaragoza). Zaragoza, Institución Fernando El Católico.

IRANZO MuÑío, María Teresa y ORTEGA ORTEGA, Julián M. (2011) «Disciplina agraria y reorganización del poblamiento bajomedieval en el territorio de la Comunidad de aldeas de Daroca», Aragón en la Edad Media, 22: 67-126. 